\title{
INFLUÊNCIA DAS TECNOLOGIAS DE INFORMAÇÃO E COMUNICAÇÃO (TICS) NO EMPREGO DO ARGUMENTO DE AUTORIDADE NA ESCRITA DIGITAL: REVISITANDO UMA NOÇÃO
}

\author{
Renan Belmonte Mazzola ${ }^{1}$ - UninCor/MG - mazzola.renan@gmail.com
}

\begin{abstract}
Resumo: Este trabalho objetiva analisar alguns aspectos do funcionamento do argumento de autoridade na escrita digital hoje a partir dos estudos de argumentação e retórica e do campo dos letramentos digitais, com vistas a explorar possibilidades de ensino em aulas de produção textual no contexto da educação básica brasileira. Este trabalho justifica-se por interrogar um gesto de escrita - as manifestações de credibilidade de um argumento qualquer - muito frequente na Web 2.0. Para este fim, realizamos um levantamento dos letramentos digitais e nos aprofundamos nos letramentos em hipertexto e em informação. Em seguida, resgatamos as definições de argumento de autoridade no campo da retórica e da argumentação. Por fim, analisamos um post de rede social em que o argumento de autoridade ganha novos contornos e discutimos esses deslocamentos no campo do ensino.
\end{abstract}

Palavras-chave: retórica; letramento digital; argumento de autoridade; escrita digital; produção textual.

\section{THE INFLUENCE OF INFORMATION AND COMMUNICATION TECHNOLOGIES (ICTS) ON AUTHORITY'S ARGUMENT USE IN THE DIGITAL WRITING: REVIEWING A NOTION}

\begin{abstract}
This paper aims to analyze some aspects of the authority's argument in digital writing today, from argumentation and rhetoric studies and from the field of digital literacies, aiming to explore the possibilities of teaching in textual production, in the context of Brazilian basic education. This work is justified by questioning an important gesture of writing - the manifestations of credibility of any argument - very frequent in Web 2.0. To this end, we have performed a survey on digital literacies and we've explored the literacy in hypertext and information. We have then retrieved the definitions of authority's argument in the field of rhetoric and argumentation. Finally, we have analyzed a social network post in which the authority's argument has shown new contours and we have discussed these displacements in the field of teaching.
\end{abstract}

Keywords: rhetoric; digital literacy; argument of authority; digital writing; text production.

\section{Introdução}

Diante de tantos debates acalorados nas redes sociais - popularizadas pelas Tecnologias de Informação e Comunicação (TICs) - muitos usuários se digladiam textualmente para tentar sobrepor seu ponto de vista e fazer calar o adversário. Os motivos de debate e confronto verbal são variados e perpassam diferentes esferas do discurso social: entre elas, a política, a religião, a economia, o ensino, a ciência, etc. Diante desse panorama, observamos a necessidade de apoiar os argumentos em alguma fonte confiável, de forma que eles possam ser "irrefutáveis". Para isso, os usuários das redes

\footnotetext{
${ }^{1}$ Professor do Programa de Mestrado em Gestão, Planejamento e Ensino e do Programa de Mestrado em Letras da Universidade Vale do Rio Verde (UninCor). Coordenador do Argumentare - Grupo de Estudos de Retórica, Discurso e Polêmicas Sociais.
} 
sociais utilizam-se dos "argumentos de autoridade" para sustentar seus raciocínios e "envergonhar seus adversários", conforme previa o domínio da erística.

A partir desse cenário, este trabalho intenciona analisar alguns aspectos do funcionamento do argumento de autoridade na escrita digital hoje - em particular nas redes sociais - a partir dos estudos de argumentação e retórica e do campo dos letramentos digitais. Essa nova configuração argumentativa online pode ser explorada, acreditamos, em aulas de produção textual que estejam atentas à algumas mutações das práticas de escrita consagradas.

Nossa hipótese é a de que o argumento de autoridade vem ganhando novos contornos, muito em função de algumas características inerentes ao ambiente virtual, que devem ser observadas e analisadas para que se ampliem as possibilidades de ensino.

Assim, colocamos duas perguntas de pesquisa, das quais partiremos: a) as definições do argumento de autoridade na teoria da argumentação correspondem ao funcionamento desse argumento no meio digital? b) como, observando as redes sociais hoje, podemos lançar um novo olhar sobre o funcionamento do argumento de autoridade?

Este trabalho justifica-se por interrogar um gesto de escrita - as formas de apoio de um argumento qualquer - muito frequente na web. Para fins de contextualização, a Web 2.0 é definida por Dudeney et al. (2016, p. 18) como uma "nova geração de ferramentas baseadas na web como blogs, wikis e sites de redes sociais, focadas na comunicação, no compartilhamento e na colaboração." Essas novas configurações elevam o estatuto do usuário, que passa a ocupar o papel não só de receptor de conteúdo midiático, mas também de produtor e colaborador no interior de uma cultura compartilhada.

Este artigo é composto de três partes, além da introdução e da conclusão. Em um primeiro momento, discutiremos os letramentos digitais e suas potencialidades voltadas à escrita de textos online. Em um segundo momento, refletiremos sobre as definições clássicas de argumento de autoridade. Por fim, apontaremos algumas configurações desse funcionamento argumentativo na escrita digital e apresentaremos os resultados obtidos.

\section{Letramentos digitais}

Letramentos digitais, para Dudeney et al. (2016, p. 17), são as "habilidades individuais e sociais necessárias para interpretar, compartilhar e criar sentido eficazmente no âmbito crescente dos canais de comunicação digitais". Dessa forma, para pensarmos em maneiras de introduzir práticas pedagógicas que envolvam a utilização da tecnologia em sala de aula, precisamos entender quais dessas "habilidades individuais e sociais" podemos potencializar com o auxílio das Tecnologias de Informação e Comunicação (TICs).

Em seu livro Letramentos digitais (2016), os autores Dudeney et al. listam 16 tipos de letramentos, divididos em quatro categorias, que podem ser trabalhados a partir do contato dos alunos com as mídias digitais. Resumiremos a seguir cada uma dessas quatro categorias.

A primeira categoria, com foco na "linguagem", engloba sete tipos de letramentos: letramento impresso, em SMS, em hipertexto, em multimídia, em jogos, móvel e em codificação. A segunda categoria, com foco na "informação", engloba quatro tipos de letramentos: letramento classificatório, em pesquisa, em informação e em filtragem. A terceira categoria, com foco em "conexões", engloba também quatro tipos de letramento: letramento pessoal, em rede, participativo e intercultural. A quarta e última categoria, com foco em "redesenho", engloba apenas um tipo de letramento: letramento remix. Vejamos o quadro a seguir: 
Tabela 1 - Quadro dos letramentos digitais (Dudeney et al., 2016, p. 21)

\begin{tabular}{|c|c|c|c|c|}
\hline Complexidade & $\begin{array}{l}\text { Primeiro foco: } \\
\text { linguagem }\end{array}$ & $\begin{array}{l}\text { Segundo foco: } \\
\text { informação }\end{array}$ & $\begin{array}{l}\text { Terceiro foco: } \\
\text { conexões }\end{array}$ & $\begin{array}{l}\text { Quarto foco: } \\
\text { redesenho }\end{array}$ \\
\hline \multirow[t]{2}{*}{ * } & $\begin{array}{l}\text {-Letramento } \\
\text { impresso }\end{array}$ & & & \\
\hline & $\begin{array}{l}\text {-Letramento em } \\
\text { SMS }\end{array}$ & & & \\
\hline$* *$ & $\begin{array}{l}\text {-Letramento em } \\
\text { hipertexto }\end{array}$ & $\begin{array}{l}\text {-Letramento } \\
\text { classificatório }\end{array}$ & & \\
\hline$* * *$ & $\begin{array}{l}\text {-Letramento em } \\
\text { multimídia }\end{array}$ & $\begin{array}{l}\text {-Letramento em } \\
\text { pesquisa } \\
\text {-Letramento em } \\
\text { informação } \\
\text {-Letramento em } \\
\text { filtragem }\end{array}$ & $\begin{array}{l}\text {-Letramento pessoal } \\
\text {-Letramento em rede } \\
\text {-Letramento } \\
\text { participativo }\end{array}$ & \\
\hline$* * * *$ & $\begin{array}{l}\text {-Letramento em } \\
\text { jogos } \\
\text {-Letramento móvel }\end{array}$ & & $\begin{array}{l}\text { Letramento } \\
\text { intercultural }\end{array}$ & \\
\hline$* * * * *$ & $\begin{array}{l}\text {-Letramento em } \\
\text { codificação }\end{array}$ & & & $\begin{array}{l}\text { Letramento } \\
\text { remix }\end{array}$ \\
\hline
\end{tabular}

Gostaríamos de explorar, neste artigo, dois tipos de letramentos: o letramento em hipertexto e o letramento em informação para, posteriormente, demonstrar como eles podem ser problematizados em sala de aula a partir da noção de argumento de autoridade.

O letramento em hipertexto define-se pela "habilidade de processar hiperlinks apropriadamente e de usá-los para incrementar com eficiência um documento ou artefato." (Dudeney et al., 2016, p. 27). "Incrementar com eficiência um documento" corresponde, retoricamente, ao funcionamento do argumento de autoridade. Podemos ler esse trecho a partir da estratégia argumentativa de produção de discursos pautada em sua incrementação, em sua maior credibilidade a partir da utilização do recurso de hiperlink. Os textos digitais que circulam em diferentes contextos, especialmente no contexto jornalístico (e, com mais discrição, no contexto científico), apresentam esse tipo de recurso, já cotidiano, aos olhos de um leitor comum. Para os autores,

Se o internetês é um novo registro linguístico, os hiperlinks são uma nova forma de pontuação (Weinberger, 2009a), que requer o desenvolvimento de um letramento em hipertexto. Retoricamente, os links exercem uma persuasão sutil, destacando os pontos mais importantes de um documento, reforçando seus argumentos principais e oferecendo um instantâneo de sua abertura e credibilidade. Navegacionalmente, os links exigem que os leitores decidam se aceitam convites para ir além do texto atual e se assumem a responsabilidade pela escolha de seus próprios percursos narrativos na rede mais ampla. Pelo fato de, às vezes, os hiperlinks criarem uma impressão enganosa com uma profusão de links para fontes similares, por exemplo, fazendo inicialmente um documento parecer mais factualmente embasado do que ele realmente é - eles carecem de um olho crítico. (Dudeney et al., 2016, p. 26-27, grifos do autor).

No contexto da produção de texto em ambientes digitais, desenvolver esse tipo de letramento em especial potencializaria as habilidades dos alunos em embasarem seus textos com fontes de credibilidade e a favor da tese defendida. 
No entanto, como foi dito, não basta que o aluno traga várias referências para o texto sem operar uma filtragem nas fontes mobilizadas. Na citação acima, lemos que há o risco em torná-lo mais passível de crítica a depender das fontes citadas.

Para que o professor possa desenvolver a crítica do aluno em relação às referências e às fontes a serem trazidas para o texto, deve-se trabalhar com um outro tipo de letramento digital que tem como objetivo atacar justamente essa questão. É o letramento em informação, definido como "habilidade de avaliar documentos e artefatos fazendo perguntas críticas, avaliando a credibilidade, comparando fontes e rastreando as origens da informação." (Dudeney et al., 2016, p. 40).

Ele é empregado para enfatizar a avaliação crítica necessária no contato entre os alunos e a quantidade de informação com que eles se deparam hoje em dia. Toda essa informação, disponível hoje na internet, não passa por determinados filtros (e censores) como é o caso os gatekeepers da mídia tradicional.

Apesar da crescente disponibilidade de publicações editadas online, existem poucos gatekeepers - editores, redatores, bibliotecários ou professores, controlando a web toda. Clay Shirky, referindo-se ao jornalismo online, afirma o seguinte: 'Checar fatos está em baixa, mas checar depois de o fato ter ocorrido está muito, muito na moda' (apud Gillmor, 2010). A responsabilidade de checar, depois de ocorrido o fato, todos os documentos e artefatos - e não apenas as notícias - cabe atualmente aos usuários. Nossos estudantes precisam aprender a fazer perguntas críticas a respeito da informação encontrada online; comparála com o patamar de conhecimento existente (portanto, eles precisam ter de memória os fatos amplamente aceitos) e, nos pontos em que seu patamar de conhecimento for inadequado, precisam comparar e contrastar, ou 'triangular', múltiplas fontes de informação. Uma maneira de demonstrar a importância do letramento em informação é começar com análises críticas de sites paródicos ou falsos, que frequentemente enganam os estudantes. É importante, como Howard Rheingold (2012) sugere, 'promover a noção de que mais infoletramento é a resposta prática à infopoluição crescente' (2017). (Dudeney et al., 2016, p. 40, grifo do autor)

Triangular as informações, checá-las, compará-las, como lemos no excerto acima, permite a seleção de fontes mais confiáveis de referência informacional. Assim, acreditamos, essas duas espécies de letramento trabalham em conjunto no momento em que o aluno elege as suas autoridades para construção dos argumentos em seus textos online.

A seguir, realizaremos um breve percurso sobre as principais definições e funcionamentos do argumento de autoridade para, mais adiante, demonstrarmos como a relação entre esses letramentos e os argumentos de autoridade podem resultar em um ensino mais contextualizado e atual sobre as formas de escrita e citação digitais.

\section{Argumento de autoridade}

Para Perelman e Tyteca (2014, p. 48), "o argumento de prestígio mais nitidamente caracterizado é o argumento de autoridade, o qual utiliza atos ou juízos de uma pessoa ou de um grupo de pessoas como meio de prova a favor de uma tese." Conhecemos três tipos mais importantes de argumento de autoridade:

i) Aquele que remete a um especialista em uma área qualquer do saber, como em "Segundo Aristóteles, os meios de persuasão através da palavra falada são três: o 
primeiro, que depende do caráter pessoal do orador (ethos); o segundo, que leva o auditório a uma certa disposição de espírito (pathos); e o terceiro, que depende do próprio discurso $(\log o s)$ no que diz respeito ao que demonstra ou visa demonstrar." Relata Fiorin (2015, p. 176) que "foi o filósofo John Locke quem deu esse nome à estratégia de valerse da chancela de uma autoridade respeitada ou de especialista num dado assunto para sustentar um ponto de vista." (cf. Locke, 1988). No exemplo acima, para Locke, a menção a Aristóteles configura "um respeito, uma reverência em relação à autoridade invocada (...). Por outro lado, seria falta de modéstia, seria mesmo uma insolência, questioná-la." (Fiorin, 2015, p. 176). Esse funcionamento caracteriza o argumento de especialista.

ii) Aquele que remete à experiência vivida, sendo esta a responsável por legitimar o ponto de vista perante uma plateia. Como exemplo, destacamos o argumento "Eu estive na Segunda Guerra, eu posso afirmar o que aconteceu de fato naquela batalha" como representativo da estratégia pela experiência. Para Fiorin (2015, p. 176), "nesse caso, quem argumenta introduz a si mesmo como prova no exame da questão, mencionando seus conhecimentos ou quaisquer outras qualidades." Sua experiência seria suficiente para terminar um debate, para por um fim à discussão, pois ele remete necessariamente a um poder pretendido: "Trabalho há dez anos nessa universidade, eu sei como fazer as coisas." Ainda segundo Fiorin (2015, p. 176), "o objetivo é levar a plateia a aceitar um ponto de vista, baseando-se na autoridade de quem enuncia, no seu conhecimento especializado, na sua credibilidade ou na sua integridade pessoal."

iii) Aquele que remete ao testemunho, o que também valida as proposições a serem defendidas. Por exemplo, "Eu vi o acidente da sacada do meu apartamento, eu vi o que aconteceu." Ou então a publicidade testemunhal que ocorre, para Fiorin (2015, p. 177), quando "alguém que goza de credibilidade assegura que usa determinado produto." O exemplo dado pelo linguista é a famosa (e polêmica) publicidade da Friboi, em que Roberto Carlos aparece comendo um pedaço de carne.

Dessa forma, podemos sintetizar o funcionamento do argumento de autoridade na seguinte fórmula:

1. O autor A afirma a proposição B.

2. Há algo de positivo em relação ao autor $A$.

3. Portanto, a proposição B é verdadeira.

O argumentum ad verecundiam, conhecido popularmente como "argumento de autoridade", serve a certas intencionalidades e finalidades comunicativas, como todo tipo de argumento. Por isso, seu emprego não escapou à polêmica e à controvérsia no campo da retórica e da argumentação:

Certos pensadores positivistas atacaram esse argumento - cuja enorme importância reconhecem na prática - tratando-o de fraudulento. É o caso de Pareto, para quem esse argumento deveria ser considerado "um meio de dar um verniz lógico às ações não-lógicas e aos sentimentos dos quais elas se originam." Seria, portanto, um pseudo-argumento destinado a camuflar a irracionalidade de nossas crenças, fazendo com que sejam sustentadas pela autoridade de pessoas eminentes, pelo consentimento de todos ou do maior número. (Perelman; Tyteca, 2014, p. 348).

Não sem razão, esse tipo de argumento é categorizado no conjunto dos "argumentos baseados na estrutura do real", conforme defendem os autores do Tratado da argumentação (2014, p. 297): 
Enquanto os argumentos quase-lógicos têm pretensão a certa validade em virtude de seu aspecto racional, derivado da relação mais ou menos estreita existente entre eles e certas fórmulas lógicas ou matemáticas, os argumentos fundamentados na estrutura do real valem-se dela para estabelecer uma solidariedade entre juízos admitidos e outros que se procura promover.

Por ser muito importante e produtivo, esse tipo de argumento frequenta diversos tipos de discurso em vários contextos. Para o que nos interessa aqui, cabe destacar que ele é ensinado insistentemente em aulas de redação escolar, quase como um "procedimento fixo" das etapas de escrita de todo texto dissertativo-argumentativo. Para os professores e professoras brasileiros - principalmente durante os anos de Ensino Médio, em que há uma maior preocupação com os exames vestibulares, para os quais a redação tem grande peso e importância - não se pode finalizar um texto dessa natureza sem a presença do ilustre argumentum ad verecundiam.

Em primeiro lugar, resgatando a origem latina do termo, trata-se de um "argumento de modéstia", que coloca o aluno na posição de quem reconhece que outros autores escreveram sobre esse tema antes dele e que, por isso, merecem respeito e reverência.

Em segundo lugar, o emprego desse tipo de argumento remete às condições do repertório do estudante, uma vez que os especialistas "citados" podem ser avaliados por hierarquias. Por exemplo, o aluno que cita a "Novela das 8" como argumento de autoridade pode ser avaliado de forma distinta daquele que cita "Michel Foucault" na defesa de determinada tese. Da mesma forma, o estudante que cita a Wikipédia como fonte de dados pode ser avaliado de forma distinta daquele que cita um periódico científico conceituado. Esse tipo de argumento atravessa, por isso, os saberes considerados de maior ou menor prestígio social. Para Perelman e Tyteca (2014, p. 350) "de todo modo, quem invoca uma autoridade se compromete: não há argumento de autoridade que não repercuta em quem o emprega."

Em terceiro lugar, por fim, o argumento de autoridade contribui para a objetividade em um texto, uma vez que o aluno é responsável por trazer diferentes vozes acerca de um tema com a finalidade de expor diversos pontos de vista sobre uma questão controversa. Para isso, as autoridades invocadas são de diferentes naturezas, conforme relatam Perelman e Tyteca (2014, p. 350): “ora será o 'parecer unânime' ou a 'opinião comum', ora certas categorias de homens, 'os cientistas', 'os filósofos', os 'Padres da Igreja', 'os profetas'; por vezes a autoridade será impessoal: 'a física', 'a doutrina', 'a religião', 'a Bíblia; por vezes se tratará de autoridades designadas pelo nome.”

A seguir, estudaremos uma forma de emprego de argumentos de autoridade na escrita digital para - a partir dessas configurações e do que discutimos sobre letramentos digitais - demonstrarmos algumas reconfigurações que esse argumento sofre em sua materialidade digital.

\section{Novas configurações de argumentação pela autoridade no meio digital}

No dia 8 de abril de 2019, em seu perfil no Twitter, Jair Bolsonaro publica uma mensagem anunciando a indicação de Abraham Weintraub para o ministério da Educação. Essa mensagem subentende a demissão do então ministro Ricardo Vélez Rodríguez: 
Jair M. Bolsonaro @jairbolsonaro.8 de abr

Comunico a todos a indicação do Professor Abraham Weintraub ao cargo de Ministro da Educação. Abraham é doutor, professor universitário e possui ampla experiência em gestão e o conhecimento necessário para a pasta. Aproveito para agradecer ao Prof. Velez pelos serviços prestados.

\section{$9,4 \mathrm{mil} \uparrow\urcorner 9,8 \mathrm{mil} \bigcirc 80 \mathrm{mil}$}

Figura 1 - Print do tuite do presidente Jair Bolsonaro ${ }^{2}$

A declaração de exoneração de um cargo do ministério gera, obviamente, muita polêmica e dá origem a opiniões de diversas naturezas nas redes sociais. Para nossas análises, elegemos o primeiro parágrafo de um post publicado por um usuário da rede social Facebook, também de 8 de abril de 2019, que comenta a exoneração. Preservaremos a identidade do autor do post, chamando-o de "Usuário"3.

Usuário

8 de abril às 14:23

Considerem este texto um desabafo. Vélez Rodrigues vinha sendo um ministro da Educação nem ruim, nem péssimo: desastroso. Nunca vi pior. Não foi por outro motivo que, em três meses, ele teve que recuar em tanta besteira, de ordenar a filmagem de crianças cantando o hino e ouvindo o slogan de campanha do presidente (https://bit.ly/2BUswgi), a indicar para uma posição estratégica no MEC uma carola, defensora de educação baseada na Bíblia (https://glo.bo/2HmqE4f). Isso, para não mencionar a humilhação a que foi submetido pela deputada Tabata Amaral (https://bit.ly/2FzM5eW); a nota oficial que soltou intimidando Ancelmo Góis, a quem acusou de ter sido "treinado em marxismo", logo após o jornalista ter denunciado uma censura realizada pelo MEC (https://bit.ly/2G4XoMy); seu desejo de que os livros didáticos neguem o golpe de 1964 e a ditadura no Brasil (https://bit.ly/2UdspaO); sua nobre declaração de que as universidades não devem ser para todos, mas para a "elite intelectual" (https://bit.ly/2HzGpG3).

O texto acima revela a opinião desse usuário sobre a demissão de Vélez. A tese apresentada é a de que Vélez Rodrigues vinha sendo um ministro da Educação péssimo, em função de várias decisões questionáveis que tomou durante os três meses em que esteve no cargo. Para sustentar essa tese e sua opinião, o autor lançou mão de sete argumentos:

\footnotetext{
${ }^{2}$ Disponível em: https://twitter.com/jairbolsonaro/status/1115261421321883648 Acesso em: 16.04.19.

${ }^{3}$ Esta pesquisa exigiu uma etapa de coleta de alguns posts - da rede social Facebook - que fossem representativos do uso de hipertexto em suas argumentações. Após nos depararmos com o post desse usuário, que faz parte da rede social do pesquisador, checou-se se o texto foi publicado sob a chancela da opção "Público", o que foi confirmado. Quando alguém posta algo nessa rede social, é possível escolher entre cinco opções de compartilhamento: a) "Público", qualquer pessoa dentro ou fora do Facebook pode ter acesso a essa informação; b) "Amigos", seus amigos, todas as pessoas marcadas e os amigos delas podem ter acesso à informação; c) "Amigos, exceto X", não mostra a alguns amigos; d) "Amigos específicos", mostra somente para alguns amigos; e e) "Somente eu", visível somente para o autor do post e para os amigos marcados. Além disso, o pesquisador informou o usuário sobre a pesquisa, de que este artigo é parte.
} 
Tese: Vélez Rodrigues vinha sendo um ministro da Educação desastroso; Argumento 1: Vélez ordenou a filmagem de crianças cantando o hino e ouvindo o slogan de campanha do presidente (https://bit.ly/2BUswgi);

Argumento 2: Vélez indicou para uma posição estratégica no MEC uma carola, defensora de educação baseada na Bíblia (https://glo.bo/2HmqE4f);

Argumento 3: Vélez sofreu humilhação da deputada Tabata Amaral (https://bit.ly/2FzM5eW);

Argumento 4: Vélez soltou uma nota oficial intimidando Ancelmo Góis, a quem acusou de ter sido "treinado em marxismo" (https://bit.ly/2G4XoMy);

Argumento 5: Ancelmo Góis, pouco antes disso, tinha denunciado uma censura realizada pelo MEC (https://bit.ly/2G4XoMy);

Argumento 6: Vélez expressou o desejo de que os livros didáticos negassem o golpe de 1964 e a Ditadura no Brasil (https://bit.ly/2UdspaO);

Argumento 7: Vélez declarou que as universidades não devem ser para todos, mas para a "elite intelectual" (https://bit.ly/2HzGpG3).

Do ponto de vista retórico e argumentativo, o interessante a se notar aqui é que esses argumentos são respaldados em links de fontes de notícia "confiáveis", o que caracterizaria o funcionamento de um argumento de autoridade - isto é, tem-se a ideia de que "os fatos aconteceram e foram noticiados pelas fontes mencionadas". Vejamos a seguir a lista das fontes mencionadas pelo autor do post, respeitando a ordem da listagem acima:

1. Fonte: Estadão (Blog de Renata Cafardo)

Manchete: "MEC manda email para escolas pedindo que cantem o hino e leiam slogan da campanha". Data: 25/02/2019.

2. Fonte: Época Manchete: "Quem é Iolene Lima, uma evangélica entre olavetes e militares no Mec". Data: 15/03/19.

3. Fonte: El País

Manchete: "A jovem deputada que jogou contra as cordas o ministro da Educação e sua 'lista de desejos' ". Data: 29/03/19.

4. Fonte: Folha de S. Paulo

Manchete: "Ministério cita KGB e diz que jornalista foi treinado pelo Partido Comunista Soviético". Data: 31/01/19.

5. Fonte: Folha de S. Paulo (idem)

Manchete: "Ministério cita KGB e diz que jornalista foi treinado pelo Partido Comunista Soviético". Data: 31/01/19.

6. Fonte: Folha de S. Paulo

Manchete: "Ministro diz que não houve golpe em 1964 e que livros didáticos vão mudar". Data: 03/04/19.

7. Fonte: Valor Econômico

Manchete: " 'Ideia de universidade para todos não existe', diz ministro da Educação.” Data: 28/01/19.

O autor do post se utiliza de diversos veículos de mídia conhecidos no Brasil para remeter o leitor às notícias originais através dos links. Ele cita Estadão, Época, El País, Folha de S. Paulo e Valor Econômico. Como consequência, seu texto torna-se digno de credibilidade, uma vez que o leitor é redirecionado às informações mais detalhadas, caso queira buscá-las. A seleção dessas fontes (e não outras) contribuem para a sustentação de 
sua tese inicial, respaldada por sua opinião com relação a Vélez: "desastroso", e "nunca ter visto pior".

Do ponto de vista formal, esses argumentos de autoridade não são apresentados em sua expressão canônica, como em "Segundo o Estadão, Mec manda email para escolas pedindo que cantem e leiam slogan da campanha, e Vélez teve de recuar nessa besteira" (Argumento 1). Os links encontram-se em sua expressão reduzida após os argumentos principais, entre parênteses, em formatos sintéticos como glo.bo e bit.ly, que não comprometem o estilo do texto e a fluência de leitura. Caso contrário, as várias linhas de links extensos poderiam deixar pesada a leitura e mesmo torná-la desinteressante. A expressão formal assumida aqui é a seguinte:

Tese $\leftarrow \quad$ Argumento 1 [link de credibilidade]

Argumento 2 [link de credibilidade]

Argumento 3 [link de credibilidade]

Argumento 4 [link de credibilidade]

Argumento 5 [link de credibilidade]

Argumento 6 [link de credibilidade]

Argumento 7 [link de credibilidade]

Argumentos de autoridade

O mecanismo hipertextual, nesse caso, atua na configuração de um argumento de autoridade, pelo fato de os links não atuarem somente na dimensão da "informatividade", mas também na dimensão da "argumentatividade" do texto analisado.

As fontes selecionadas revelam a imagem do auditório construída pelo autor do post, uma vez que foram escolhidas fontes que, acreditamos, a maioria dos leitores das redes sociais consideram como "dignas de credibilidade". Foram evitadas fontes desconhecidas de notícia e que não possuíam um ethos de confiabilidade previamente construído e instaurado na doxa social no que se refere a veículos de comunicação mais prestigiados. Dessa forma, ao escolher esses veículos e não outros, o autor foi mais efetivo na persuasão de um auditório de redes sociais, de leitores que checam as fontes de informação em função das facilidades proporcionadas pelas TICs.

\section{Conclusões}

Neste trabalho, mobilizamos as discussões sobre os letramentos digitais para remapearmos nossa relação com a escrita digital por meio das Tecnologias de Informação e Comunicação - TICs - nas condições de conectividade atuais e observarmos as estratégias mobilizadas em um texto das redes sociais.

Ao realizarmos um percurso pelas definições e funcionamentos do argumento de autoridade na teoria retórica e argumentativa, demonstramos as potencialidades de seu emprego na efetivação da persuasão.

Partindo das definições de letramento digital em hipertexto, demonstramos porque "Retoricamente, os links exercem uma persuasão sutil, destacando os pontos mais importantes de um documento, reforçando seus argumentos principais e oferecendo um instantâneo de sua abertura e credibilidade", conforme ressaltaram os pesquisadores Dudeney et al. (2016, p. 26-27).

Com relação ao letramento digital em informação, entendemos as configurações atuais de escrita e leitura na rede, uma vez que, ainda segundo os pesquisadores (2016, p. 40) "a responsabilidade de checar, depois de ocorrido o fato, todos os documentos e 
artefatos - e não apenas as notícias - cabe atualmente aos usuários." Esse processo, como vimos, é explorado na escrita digital em posts do Facebook para que as teses sejam melhor sustentadas e a persuasão seja mais efetiva.

Por um lado, a escrita mediada pelas novas tecnologias permite com facilidade a inserção de links e hipertextos para fundamentar uma tese. Por outro lado, ao analisar o emprego desse recurso em um post publicado em rede social, notamos que seu funcionamento é, em alguma medida, distinto da forma canônica de manifestação da estratégia argumentativa de autoridade. Todos esses fatores contribuem para a reconfiguração de um novo fazer ad verecundiam em textos digitais, e essas novas reconfigurações podem ser exploradas em contextos de ensino que se relacionem com as disciplinas de produção textual hoje.

$\mathrm{Na}$ sala de aula, durante uma atividade de escrita online, é possível trabalhar com os alunos tanto as funcionalidades do argumento de autoridade quanto a qualidade das informações e das fontes mobilizadas, fornecendo ao aluno as bases para a crítica. $\mathrm{O}$ desenvolvimento do pensamento crítico é um dos objetivos a serem alcançados ao término da educação básica, segundo a lei 9.394/96 (Brasil, 1996, grifo nosso): "O ensino médio, etapa final da educação básica, com duração mínima de três anos, terá como finalidades (...) o aprimoramento do educando como pessoa humana, incluindo a formação ética e o desenvolvimento da autonomia intelectual e do pensamento crítico".

No contexto de ensino atual, o pensamento crítico é desenvolvido, em grande parte, nas aulas de produção textual (ou de redação). Nessas disciplinas, tem-se a materialização das ideias dos educandos sob a forma de textos, que podem ser avaliados pelos professores com relação à criticidade ali presente.

Com o recurso à autoridade a partir de fontes midiáticas legitimadas, que têm o costume de checar as fontes de que se utilizam para produzir a notícia jornalística, abrese uma possibilidade de barrar a proliferação das Fake News - notícias falsas reproduzidas indefinidamente sem a checagem dos dados e fatos ali presentes. Dessa forma, o trabalho com o letramento em hipertex to e o letramento em informação no contexto da Educação básica brasileira seria um caminho para a construção de uma consciência mais que crítica: cidadã.

\section{Referências bibliográficas}

BRASIL, L. D. B. Lei 9394/96 - Lei de Diretrizes e Bases da Educação Nacional, 1996. Disponível em: http://www.planalto.gov.br/ccivil_03/leis/L9394.htm. Acesso em: 22 abr. 2019.

DUDENEY, G.; HOCKLY, N.; PEGRUM, M. Letramentos digitais. Trad. Marcos

Marcionilo. 1a ed. São Paulo: Parábola Editorial, 2016.

FIORIN, J. L. Argumentação. 1a ed. São Paulo: Contexto, 2015.

LOCKE, J. Ensaio acerca do entendimento humano. São Paulo: Nova Cultural, 1988. PERELMAN, C.; OLBRECHTS-TYTECA, L. Tratado da argumentação: a nova retórica. Trad. Maria Ermantina de Almeida Prado Galvão. 3a ed. São Paulo: Martins Fontes, 2014. 